\title{
HUBUNGAN DERAJAT KEPRIBADIAN INTROVERT DENGAN SINDROMA PRAMENSTRUASI
}

\author{
Rochmadina Suci Bestari \\ Fakultas Kedokteran Universitas Muhammadiyah Surakarta \\ Correspondence to : dr. Rochmadina Suci Bestari \\ Email : rochmadina@gmail.com
}

\begin{abstract}
Introvert people tend to have distress. Psicosomatic manifestation from distress on women can be appeared as premenstrual syndrome. The aim of this study is to know the correlation between social introversion stage and premenstrual syndrome. This study is an analitic observasional study with cross sectional approach, which was held on November 2006 on Medical Faculty UNS Solo. Samples were taken by purposive sampling with restriction on new university studentsclass 2006 Medical Faculty of UNS. The requirements are : (1) on premenstrual or menstrual phase, and (2) does not have reproduction organ disease. Subject filled (1) Kuesioner Riwayat Menstruasi dan Ginekologi (Gynecology and Menstrual History Questionair) to know subject's menstrual cycle, (2) Kuesioner Skala L-MMPI (L-MMPI Scale Questionair) to state honesty in answering questions given, (3) Kuesioner Sindroma Pramenstruasi (Premenstrual Syndrome Questionair) consisted of pramenstrual syndrome's aspects, (4) Kuesioner Skala-0 MMPI (MMPI 0-Scale Questionair) to state social introversion stage. It's obtained 42 subjects data. Social introversion stage (SI) and premenstrual syndrome (PMS) data were then analyzed with (1) Normality test by Shapiro Wilk, and (2) Hypothetic test by Pearson correlation used SPSS 11.0 for Windows computer program.Results of this study are (1) Premenstrual subjects are bigger amount than non-premenstrual subjects $(88,1 \%$ vs $11,9 \%)$, (2) there is significant positive correlation between social introversion stage and premenstrual syndrome with strong correlation $(r=0,551 ; P<0,05)$. The conclusion of this study is there is significant positive correlation between social introversion stage and premenstrual syndrome.
\end{abstract}

Keywords: Social introversion, premenstrual syndrome

\section{PENDAHULUAN}

Bagi Individu, stres adalah hal biasa yang ditemui dalam kehidupan sehari-hari. Ada stres yang perlu bagi seseorang agar dia berfungsi secara normal (Atkinson dkk, 1996). Akan tetapi ada pula stres yang merugikan. Dr. Hans Selye merumuskan stres sebagai tanggapan tubuh yang sifatnya non spesifik terhadap tuntutan atasnya. Jika tuntutan itu berlebihan maka disebut distres (Hawari, 1997).

Manifestasi stres tidak sama pada semua orang. Hal tersebut terjadi karena adanya bentuk stresor yang lain yang tidak teramati di sekitar stresor yang ada atau adanya perbedaan penilaian yang menyebabkan stresor yang sama mempunyai arti yang berbeda. Kedua hal tersebut sebagai mediator yang mempunyai arti mengarahkan atau memperantarai (mediator) pengaruh stresor terhadap timbulnya dampak stres. Mediator atau sumber penanggulangan (coping resources) dapat berasal dari personal, antara lain tipe kepribadian (Freud, 1986).
Ciri orang yang tahan stres adalah mereka terlibat lebih aktif dengan pekerjaan dan kehidupan masyarakat mereka (Atkinson, 1996). Ciri tersebut didapatkan pada kepribadian ekstrovert, yang bersifat sikap hatinya terbuka, mudah bergaul, hubungan dengan orang lain lancar, aktif, optimis, dinamis, ramah dan hangat (Suryabrata, 2000). Sedangkan kepribadian introvert bersifat penyesuaiannya dengan dunia luar kurang baik, jiwanya tertutup, sukar bergaul, sukar berhubungan dengan orang lain, kurang dapat menarik hati orang lain (Agus, 1991), sehingga stres yang dialaminya menjadi distres.

Stres atau emosi bisa menimbulkan perubahan fisik dalam organ yang dipersarafi oleh susunan saraf otonom dan di mana satu jenis personalitas berhubungan dengan penyakit tertentu (Ingram, 1996). Sementara Eysenck menyatakan bahwa individu introvert berkecenderungan untuk mengembangkan gejala-gejala ketakutan dan depresi yang ditandai oleh mudah tersinggung, apati, saraf otonom labil, mudah terluka, mudah 
gugup, rendah diri, mudah melamun, dan sukar tidur (Suryabrata, 2000).

Stres yang gawat atau distres (berlangsung melalui sistem urat saraf pusat untuk mengubah keseimbangan hormon) dapat juga merusak respon daya tahan seseorang (Atkinson, 1996).

Pada wanita, terdapat fase perubahan keseimbangan hormonal yang dialami secara berkala tiap bulan, yaitu menstruasi. Tujuh puluh lima persen wanita mengalami gejala-gejala selama hari-hari sebelum menstruasi, di mana gejala-gejala itu berulang tiap bulan (Silberstein, 2003). Gejala-gejala tersebut dinamakan sindroma pramenstruasi. Sindroma pramenstruasi biasa timbul satu minggu sampai beberapa hari sebelum menstruasi, dan menghilang sesudah menstruasi datang, walaupun kadang berlangsung terus sampai menstruasi berhenti (Simanjuntak, 2005). Lebih dari $90 \%$ wanita yang mengalami gejala-gejala sebelum menstruasi itu mengalami perubahan pada perilaku dan kehidupan mereka sehingga dapat mempengaruhi keluarga, kehidupan sosial, dan lingkungan kerja (Campagne, 2006).Perubahan emosi dan stres pada sindroma pramenstruasi berkaitan dengan kepribadian (Bisson, 1989).

Sepengetahuan peneliti, penelitian tentang derajat kepribadian introvert dengan sindroma pramenstruasi belum pernah dilakukan di Surakarta. Oleh karena itu, penting kiranya dilakukan penelitian untuk mengetahui hubungan orang berkepribadian introvert dengan sindroma pramenstruasi.

Penelitian ini bertujuan untuk mengetahui hubungan derajat kepribadian introvert dengan sindroma pramenstruasi sehingga diharapkan dapat memberi masukan bagi pihak terkait di Fakultas Kedokteran UNS, para klinisi pada umumnya dan mahasiswa Fakultas Kedokteran UNS pada khususnya.

\section{METODE}

Jenis penelitian ini adalah observasional analitik dengan pendekatan cross sectional (Taufiqurohman, 2004). Subyek yang diambil adalah mahasiswa baru angkatan 2006 Fakultas Kedokteran UNS yang mempunyai kriteria inklusi sedang mengalami fase pramenstruasi atau menstruasi di mana fase pramenstruasi dimulai satu minggu sebelum menstruasi (Simanjuntak, 2005) sedangkan kriteria eksklusinya sedang menderita penyakit organ reproduksi. Pengambilan sampel dilakukan dengan purposive sampling, yaitu memilih sampel berdasarkan ciri-ciri atau sifat tertentu yang berkaitan dengan karakteristik populasi (Taufiqurohman, 2004). Sedangkan teknik pemilihan subyek/sampel dengan cara restriksi karena menggunakan kriteria inklusi dan eksklusi (Murti, 2003).Variabel bebas dan variabel tergantung dalam penelitian ini berskala interval sehingga analisis data yang digunakan adalah uji korelasi Pearson (r) (Murti, 2003).

\section{HASIL DAN PEMBAHASAN}

Penelitian dilakukan pada bulan November 2006 dengan cara menyebar kuesioner kepada mahasiswi-mahasiswi angkatan 2006 Fakultas Kedokteran UNS Surakarta. Setelah melalui protokol penelitian, didapatkan 42 kuesioner yang dapat dianalisis, yaitu:

Tabel 1. Data sindroma pramenstruasi dan derajat kepribadian introvert

\begin{tabular}{ccc}
\hline No. & Sindroma Pramenstruasi & $\begin{array}{c}\text { Derajat Kepribadian } \\
\text { Introvert }\end{array}$ \\
\hline 1. & 99 & 44 \\
2. & 83 & 28 \\
3. & 72 & 33 \\
4. & 75 & 27 \\
5. & 81 & 25 \\
6. & 71 & 31 \\
7. & 59 & 24 \\
8. & 72 & 27 \\
9. & 77 & 27 \\
10. & 87 & 38 \\
11. & 53 & 15 \\
\hline
\end{tabular}




\begin{tabular}{|c|c|c|}
\hline 12. & 52 & 24 \\
\hline 13. & 74 & 27 \\
\hline 14. & 78 & 17 \\
\hline 15. & 67 & 35 \\
\hline 16. & 103 & 31 \\
\hline 17. & 62 & 18 \\
\hline 18. & 70 & 17 \\
\hline 19. & 70 & 25 \\
\hline 20. & 63 & 20 \\
\hline 21. & 68 & 25 \\
\hline 22. & 40 & 16 \\
\hline 23. & 73 & 27 \\
\hline 24. & 95 & 43 \\
\hline 25. & 63 & 19 \\
\hline 26. & 44 & 25 \\
\hline 27. & 78 & 48 \\
\hline 28. & 70 & 25 \\
\hline 29. & 96 & 29 \\
\hline 30. & 62 & 27 \\
\hline 31. & 60 & 34 \\
\hline 32. & 80 & 32 \\
\hline 33. & 97 & 36 \\
\hline 34. & 96 & 30 \\
\hline 35. & 64 & 27 \\
\hline 36. & 78 & 25 \\
\hline 37. & 69 & 42 \\
\hline 38. & 70 & 18 \\
\hline 39. & 61 & 15 \\
\hline 40. & 85 & 26 \\
\hline 41. & 73 & 17 \\
\hline 42. & 84 & 43 \\
\hline
\end{tabular}

Dari data tersebut, didapatkan karakteristik responden sebagai berikut:

Tabel 2. Distribusi responden menurut sindroma pramenstruasi

\begin{tabular}{cclcc}
\hline No. & Nilai & \multicolumn{1}{c}{ Interpretasi } & Jumlah & Persentase \\
\hline 1. & $30-60$ & Tidak mengalami sindroma pramenstruasi & 5 & 11,9 \\
2. & $61-120$ & Mengalami sindroma pramenstruasi & 37 & 88,1 \\
& & Jumlah & 42 & 100,0 \\
\hline \multicolumn{2}{l}{ Sumber: } & &
\end{tabular}

Berdasarkan tabel di atas, jumlah responden yang

mengalami sindroma pramenstruasi lebih banyak, yaitu $88,1 \%$ dari jumlah seluruh responden. 


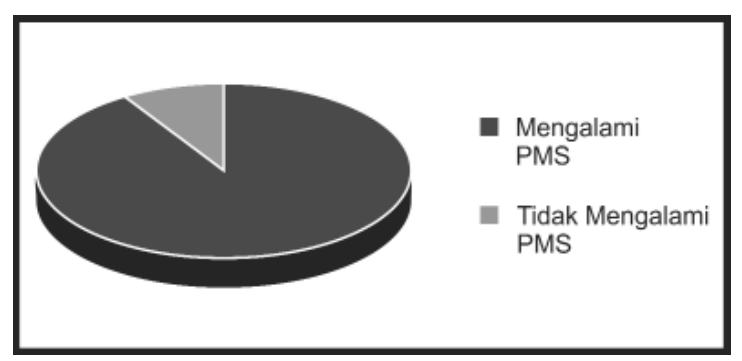

Grafik 1. Distribusi responden menurut sindroma pramenstruasi

Data yang diperoleh di atas kemudian dilakukan analisis data yang terdiri dari dua langkah, yaitu (1) uji normalitas data dan (2) uji hipotesis dengan korelasi Pearson, menggunakan program komputer SPSS 11.0 for Windows.
1. Uji normalitas data

Uji normalitas data dilakukan untuk mengetahui distribusi data normal atau tidak (Santoso, 2006). Suatu data dikatakan mempunyai sebaran normal jika nilai $\mathrm{p}>0,05$ (Dahlan, 2005). Hasilnya sebagai berikut.

Tabel 3. Tes Normalitas

\begin{tabular}{ccccccc} 
& \multicolumn{3}{c}{ Kolmogorov-Smimov $^{3}$} & \multicolumn{3}{c}{ Shapiro-Wilk } \\
\cline { 2 - 7 } & Statistic & df & Sig. & Statistic & df & Sig. \\
\cline { 2 - 7 } PMS &, 083 & 42 &, $200^{*}$ &, 977 & 42 &, 560 \\
SI &, 151 & 42 &, 018 &, 943 & 42 &, 037 \\
\hline
\end{tabular}

*. This is a lower bound of the true significance

a. Lilliefors Significance Correction

Interpretasi hasil uji normalitas data menggunakan Shapiro-Wilk karena sampel berjumlah $\leq 50$ (Dahlan, 2005), didapatkan nilai signifikansi $\mathrm{p}=0,560$ untuk data PMS dan $\mathrm{p}=0,037$ untuk data SI. Dari tabel di atas, dapat disimpulkan bahwa data PMS (Premenstrual Syndrome) mempunyai sebaran normal atau simetris, sedangkan data SI (Social Introversion) tidak.

Untuk menormalkan sebaran data, dilakukan proses transformasi data (Dahlan, 2005). Salah satu cara transformasi data dalam SPSS adalah menggunakan fungsi log. Hasil tes normalitas datanya adalah sebagai berikut.

Tabel 4. Tes normalitas data setelah transformasi data SI

\begin{tabular}{|c|c|c|c|c|c|c|}
\hline & \multicolumn{3}{|c|}{ Kolmogorov-Smirnov $^{3}$} & \multicolumn{3}{|c|}{ Shapiro-Wilk } \\
\hline & Statistic & $\mathrm{df}$ & Sig. & Statistic & $\mathrm{df}$ & Sig. \\
\hline trans_si & ,141 & 42 & ,034 & ,959 & 42 & 131 \\
\hline
\end{tabular}

a. Lilliefors Significance Correction

Interpretasi data menggunakan ShapiroWilk karena sampel berjumlah $\leq 50$, didapatkan nilai kemaknaan $\mathrm{p}=0,131$ untuk data SI (Social Introversion) setelah ditransformasi. Dengan demikian dapat diambil kesimpulan bahwa data tersebut sudah mempunyai distribusi normal. Data setelah ditransformasi adalah sebagai berikut.

Tabel 5. Data setelah ditransformasi

\begin{tabular}{cccc}
\hline & PMG & SI & trans_si \\
\hline 1 & 99 & 44 & 1,64 \\
2 & 83 & 28 & 1,45 \\
3 & 72 & 33 & 1,52 \\
\hline
\end{tabular}




\begin{tabular}{|c|c|c|c|}
\hline 4 & 75 & 27 & 1,43 \\
\hline 5 & 81 & 25 & 1,40 \\
\hline 6 & 71 & 31 & 1,49 \\
\hline 7 & 59 & 24 & 1,38 \\
\hline 8 & 72 & 27 & 1,43 \\
\hline 9 & 77 & 27 & 1,43 \\
\hline 10 & 87 & 38 & 1,58 \\
\hline 11 & 53 & 15 & 1,18 \\
\hline 12 & 52 & 24 & 1,38 \\
\hline 13 & 74 & 27 & 1,43 \\
\hline 14 & 78 & 17 & 1,23 \\
\hline 15 & 67 & 35 & 1,54 \\
\hline 16 & 103 & 31 & 1,49 \\
\hline 17 & 62 & 18 & 1,26 \\
\hline 18 & 70 & 17 & 1,23 \\
\hline 19 & 70 & 25 & 1,40 \\
\hline 20 & 63 & 20 & 1,30 \\
\hline 21 & 68 & 25 & 1,40 \\
\hline 22 & 40 & 16 & 1,20 \\
\hline 23 & 73 & 27 & 1,43 \\
\hline 24 & 95 & 43 & 1,63 \\
\hline 25 & 63 & 19 & 1,28 \\
\hline 26 & 44 & 25 & 1,40 \\
\hline 27 & 78 & 48 & 1,68 \\
\hline 28 & 70 & 25 & 1,40 \\
\hline 29 & 96 & 29 & 1,46 \\
\hline 30 & 62 & 27 & 1,43 \\
\hline 31 & 60 & 34 & 1,53 \\
\hline 32 & 80 & 32 & 1,51 \\
\hline 33 & 97 & 36 & 1,56 \\
\hline 34 & 96 & 30 & 1,48 \\
\hline 35 & 64 & 27 & 1,43 \\
\hline 36 & 78 & 25 & 1,40 \\
\hline 37 & 69 & 42 & 1,62 \\
\hline 38 & 70 & 18 & 1,26 \\
\hline 39 & 61 & 15 & 1,18 \\
\hline 40 & 85 & 26 & 1,41 \\
\hline 41 & 73 & 17 & 1,23 \\
\hline 42 & 84 & 43 & 1,63 \\
\hline
\end{tabular}

\section{Uji Korelasi Pearson}

Syarat uji parametrik adalah data mempunyai sebaran normal (Dahlan, 2004; Wahana Komputer Semarang, 2004) dan sampel berjumlah lebih dari 30 (Nugroho, 2005). Kedua data dalam penelitian ini telah mempunyai sebaran normal dan sampel berjumlah 42, maka uji Korelasi Pearson dapat dipakai untuk analisis data. Hasilnya sebagai berikut.
Tabel 6. Uji Korelasi Pearson

\begin{tabular}{llcc} 
& & PMS & trans_si \\
\cline { 3 - 4 } PMS & Pearson Correlation & 1 &, $551^{* * *}$ \\
& Sig, (2-tailed) & &, 000 \\
& $\mathrm{~N}$ & 42 & 42 \\
trans_si & Pearson Correlation &, $551^{* *}$ & 1 \\
& Sig, (2-tailed) &, 000 & \\
& $\mathrm{~N}$ & 42 & 42 \\
\hline$* *$. Correlation is significant at the 0.01 level (2-tailed).
\end{tabular}


Untuk menilai kema knaan korelasi antar dua variabel, digunakan nilai $\mathrm{P}$ (Sig.). Terdapat korelasi yang bermakna antar dua variabel jika nilai $\mathrm{P}<0,05$ (Dahlan, 2005). Interpretasi hasil analisis dengan uji korelasi Pearson pada penelitian ini, didapatkan nilai $\mathrm{P}=0,000$ menunjukkan bahwa korelasi antara skor PMS dan skor SI adalah bermakna.

Sedangkan nilai korelasi Pearson (r) adalah 0,551 . Hal ini menunjukkan dua hal, yaitu arah korelasi dan kekuatan korelasi. Nilai korelasi Pearsonnya adalah positif, berarti hubungannya searah. Hal itu menunjukkan bahwa semakin besar nilai suatu variabel, semakin besar pula nilai variabel yang lain (Dahlan, 2005). Nilai korelasinya 0,551 , berarti kekuatan korelasinya kuat (Nugroho, 2005; Sarwono, 2006).

Dari analisis data dengan menggunakan uji korelasi Pearson, dapat disimpulkan bahwa Ho $(r \leq 0)$ ditolak, dan $\mathrm{H} 1$ diterima. Berarti ada hubungan positif antara derajat kepribadian introvert dan sindroma pramenstruasi.

Dari hasil penelitian didapatkan bahwa responden yang mengalami sindroma pramenstruasi sebanyak $88,1 \%$. Hal ini sesuai dengan pernyataan Silberstein bahwa lebih dari $75 \%$ wanita mengalami sindroma pramenstruasi (Silberstein, 2003). Mengingat tingginya prevalensi wanita yang mengalami sindroma pramenstruasi dan beratnya gangguan yang dapat muncul, sebaiknya masalah ini lebih diperhatikan.

Analisis data hubungan derajat kepribadian introvert dengan sindroma pramenstruasi dengan uji korelasi Pearson menggunakan program SPSS 11.0 for Windows didapatkan nilai kemaknaan $\mathrm{p}=0,000$ menunjukkan bahwa korelasi antara skor PMS dan skor SI adalah bermakna. Sedangkan nilai korelasi Pearson 0,551 menunjukkan bahwa terdapat korelasi positif dengan kekuatan korelasi kuat.

Orang introvert bersifat penyesuaiannya dengan dunia luar kurang baik, jiwanya tertutup, sukar bergaul (Agus, 1991), berkecenderungan untuk mengembangkan gejala-gejala ketakutan dan depresi, yang ditandai oleh kecenderungan obsesi, mudah tersinggung, apati, saraf otonomnya labil, gampang terluka, mudah gugup, rendah diri, mudah melamun, dan sukar tidur (Suryabrata, 2000).

Bisson menyatakan bahwa perubahan emosi dan stres pada sindroma pramenstruasi berkaitan dengan kepribadian (Bisson, 1989). Kepribadian yang ditandai dengan kecurigaan yang berlebihan dan menimbulkan depresi (depressed distrust) serta sangat sensitif terhadap simulasi psikologi (irritabel), yaitu kepribadian introvert.

Hasil berupa korelasi positif antara derajat kepribadian introvert dan sindroma pramenstruasi menunjukkan bahwa semakin tinggi derajat kepribadian introvert semakin tinggi pula tingkat keparahan sindroma pramenstruasi.

Kesimpulan pada penelitian ini dapat digeneralisasikan pada populasi penelitianm yaitu mahasiswi kedokteran UNS angkatan 2006. Untuk dapat melakukan generalisasi kesimpulan pada populasi yang lain atau yang lebih luas, diperlukan penelitian lebih lanjut.

Pada penelitian ini, analisisnya hanya menunjukkan korelasi antara dua variabel, yaitu derajat kepribadian introvert dan sindroma pramenstruasi. Untuk mengetahui bahwa hubungan antara keduanya adalah hubungan sebab akibat, atau variabel yang satu mempengaruhi variabel yang lain, maka diperlukan penelitian lebih lanjut.

Pada penelitian ini, faktor perancu (confounding factor) dari sindroma pramenstruasi yang diperhitungkan hanyalah penyakit organik. Faktor perancu lain tidak diperhitungkan, sehingga diperlukan penelitian lebih lanjut.

\section{SIMPULAN}

1. Dari hasil penelitian ini, jumlah responden yang mengalami sindroma pramenstruasi lebih besar daripada yang tidak mengalami sindroma pramenstruasi $(88,1 \%$ vs $11,9 \%)$

2. Ada korelasi positif yang bermakna antara derajat kepribadian introvert dan sindroma pramenstruasi dengan kekuatan korelasi kuat $(\mathrm{r}=0,551 ; \mathrm{P}<0,05)$.

\section{SARAN}

Mengingat tingginya prevalensi wanita yang mengalami sindroma pramenstruasi, sebaiknya masalah ini lebih diperhatikan oleh para klinisi pada umumnya dan mahasiswa Fakultas Kedokteran pada khususnya.

1. Sebaiknya wanita yang introvert dipersiapkan untuk menerima kenyataan bahwa dia mempunyai kecenderungan mengalami sindroma pramenstruasi, agar tidak menjadi gangguan psikiatri lebih parah. 
2. Sebaiknya dilakukan penelitian pada populasi lain atau yang lebih luas untuk dapat melakukan generalisasi kesimpulan yang sama.

\section{DAFTAR PUSTAKA}

Atkinson,dkk (1996). Pengantar Psikologi. Jilid 2. Jakarta: Erlangga, pp: 222-37

Agus S (1991). Psikologi Kepribadian. Jakarta: PT. Rineka Cipta, pp: 69-70

Benson RC (1983). Gynecology and Obstetrics. In: Krupp MA, Chalton MJ. Current Medical Diagnosis and Treatment. California: Lage Medical Publications, p: 437

Bisson C, Whissell (1989). Will premenstrual syndrome produce a Miss Hyde?: evidence from daily administration of the Emotions Profile Index. Psychol Rep. 65(1):179-84. www.pubmed.com (11 September 2006)

Campagne DM, Campagne G (2006). The premenstrual syndrome revisted. Eur $J$ Obstet Gynecol Reprod Biol.www. pubmed.com (9 September 2006)

Dahlan MS (2005). Statistik untuk Kedokteran dan Kesehatan. Jakarta: PT. Arkans

Freud S (1986). Psikologi: Sebuah Pengantar (terjemahan). Cetakan 1. Jakarta: PT. Pradnya Paramita

Graham JR (1987). The MMPI: A Practical Guide. New York: Oxford University Press Inc., pp:68-70

Gise LH (1995). Premenstrual Syndrome. In: Lemcke DP dkk. Primary Care of Women. 1st edition. USA: Prentice-Hall International Inc., pp: 410-2

Hawari D (1997). Al-Qur'an: Ilmu Kesehatan Jiwa. Yogyakarta: PT. Dana Bakti Prima Yassa

Ingram IM, Timbury GC, Mowbray RM (1995). Hubungan penyakit psikiatri dan fisik. Dalam :

Peter Anugrah. Catatan Kuliah Psikiatri (terjemahan). Edisi ke-6. Cetakan 2. Jakarta: PT. Gramedia, p: 92

McHichi alami Kh, Tahiri SM, Moussaoui D, Kadri N (2002). Assessment of premenstrual dysphoric disorder symptoms: population of women in Casablanca. Encephale. 28(6 Pt 1):525-30. www. pubmed.com (9 September 2006)

Murti B (2003). Prinsip dan Metode Riset Epidemiologi. Edisi ke-2. Jilid 1. Yogyakarta: Gajah Mada University Press, pp: 143-6, 175

Nugroho BA (2005). Strategi Jitu Memilih Metode Statistik Penelitian dengan SPSS. Yogyakarta: Penerbit Andi, p:35

Santoso S (2006). Menguasai Statistik di Era Reformasi denga SPSS14. Jakarta: Elex Media Computindo

Sarwono J (2006). Analisis Data Penelitian Menggunakan SPSS. Ypgyakarta: Penerbit Andi, p:86

Shanti LL (2003). Korelasi Depresi dengan Sindroma Pramenstruasi. Fakultas Kedokteran UNS. Skripsi.

Silberstein T (2003). Complications of Menstruation; Abnormal Uterine Bleeding. In: DeCherney AH, Nathan L. Current Obstetric and Gynecologic Diagnosis and Treatment. $9^{\text {th }}$ edition. New York: The McGraw-Hill Companies, 623-4

Simanjuntak P (2005). Gangguan Haid dan Siklusnya. Dalam Hanifa Wiknjosastro. Ilmu Kandungan. Edis ke-2. Cetakan 4. Jakarta: Yayasan Bina Pustaka Sarwono Prawirihardjo, p: 232

Suryabrata S (2000). Psikologi Kepribadian. Jakarta: Rajawali Press, pp: 161, 343-4

Taufiqurohman MA(2004). Pengantar Metodologi Penelitian untuk Ilmu Kesehatan. Klaten: CGSF (The Community of Self Help Group Forum), pp: 62-8

Wahana Komputer Semarang (2004). Pengolahan Data Statistik dengan SPSS12. Yogyakarta: Penerbit Andi, p: 129 